\title{
Clinical leadership and innovation
}

\author{
David J ohn Stanley \\ University of Western Australia, Australia \\ Correspondence: David John Stanley. Address: University of Western Australia, Australia. Email: \\ david.stanley@curtin.edu.au
}

Received: October 18, 2011

Accepted: December 14, 2011 Published: May 1, 2012

DOI : 10.5430/jnep.v2n2p119

URL: http://dx.doi.org/10.5430/jnep.v2n2p119

\section{Abstract}

This article suggests that effective clinical leadership leads to innovation. Innovation leads to change and that change leads to improvements in care, service, quality and professionalism. However, for this process to develop, clinical leadership needs to be clearly understood, clinical leaders need to be recognized, by their organizations and by themselves, and opportunities for genuine innovation and real change needs to be supported and fostered.

\section{Key Words}

Clinical leadership, Congruent leadership, Innovation, Change

\section{I ntroduction}

The basis of this article is that there is a link between clinical leadership and innovation ${ }^{[1]}$. As such, it is proposed that effective clinical leadership leads to innovation. Innovation leads to change, and that change leads to improvements in care, service, quality and professionalism. Real improvements in quality, care and services come from effective, insightful change and positive innovation that is derived from people who are prepared to take the lead and act on their ideas. It is not suggested that every change is positive or good. Clearly change for changes sake or change that is ill conceived or poorly planned can have negative consequences. However, change, facilitated or driven by clinical leaders, people, being innovative that leads to improvements in quality, care and services is considered valuable and essential. Jessie Jackson an American political and civil rights leader suggested that, change isn't about processes or structure it is about courageous people who are prepared to act. Thus, if a ward or a hospital or indeed the health service as a whole is to adapt and develop, there is an urgent need to identify who these courageous people are.

Baker et al., Cook, Alleyne and Jumaa, Wong and Cummings, Sirola-Karvinen and Harkäs, Murphy et al. and Stanley ${ }^{[1-7]}$ believe these courageous people are clinical leaders who employ a Congruent ${ }^{[1,8-10]}$, approach to leadership (a Congruent leader is someone who is followed because their values and beliefs are matched by their actions). This paper suggests that clinical leaders play a vital role in innovation and change and are at the forefront of clinical developments, change and innovation.

Significant improvement in an organization (wards and units) comes from shaping and developing their culture and the key to changing an organization's culture is to focus on people and the contribution they can, or do make. Hall concludes that cultural change has a far more pervasive impact on an organization than the modification of structure or changing 
processes and procedures ${ }^{[11,12]}$. This article proposes that innovation and change in clinical practice is best directed by clinical leaders, health professionals in key clinical positions that are able (like Jill) to recognize and respond appropriately to patient and service needs. By understanding what clinical leadership is, how clinical leaders link to innovation and recognizing that innovation can be anything that positively impacts on patient care or an organization's services. Genuine clinical change and innovation in practice can be facilitated.

\section{Case Study 1}

Jill was a registered nurse doing a clinical leadership unit at university. She and the other students had been asked to develop a change project proposal that looked at initiating a change in practice to improve patient care, service quality or an aspect of professional nursing. Jill worked on a cardiac rehabilitation ward and had done for 4 years. At least a dozen times every shift she or her colleagues responded to a bell in the patient's toilet as patients rang to ask for help to simply get up from the toilet. She noticed that there were two metal bars on the wall for patients to grip and assist them to stand, but they were located on the wall behind the toilet, out of the patient's reach. Jill's change project proposal was to move the bars to the wall in front of the toilet so that patients could reach out and help themselves to their feet after using the toilet. This meant more effective cardiac rehabilitation as patients began to do more for themselves (as appropriate), less calls for nurses and thus less demands on the busy nurses' time and a safer bath room environment. The bars had been behind the toilet since the ward had opened at least 30 years earlier and in all those years no one had thought to move the bars instead of constantly responding to the ringing bell. Jill's suggestion (and subsequent action) to change the location of the bars was a breakthrough and innovation that initiated an improvement in care, supported greater rehabilitation and saved nurses’ time. In doing so Jill demonstrated the actions of a clinical leader.

\section{Defining clinical leadership}

Clinical leaders are the health professionals best placed to lead change in practice and suggest innovations that impact positively on clinical quality ${ }^{[1]}$. While nurse researchers, people directing governance initiatives and even Government policy can also suggest innovations, it falls to the clinicians to interpret policy and act to initiate and support new initiatives. Indeed it is because of their contribution to the delivery of clinical care that clinical leaders are recognized for supporting and directing innovation ${ }^{[13]}$. Harper described clinical leaders as experts in a speciality practice area and who use interpersonal skills to enable nurses to deliver quality patient care ${ }^{[14]}$. This view is supported by the McKinsey Quarterly who suggest that clinical leadership is about putting clinicians at the heart of shaping and running clinical services, so as to deliver outcomes for patients not as a one off task or project, but as a central part of the clinician's professional identity ${ }^{[15]}$.

Lett sees clinical leaders as those who empower others, who are expert nurses and who lead their followers toward better health and health care ${ }^{[16]}$.Cook also recognized the key role clinical leaders have in shaping clinical care and in continually improving care through influencing others ${ }^{[17]}$. Jonas, McCay and Keogh see clinical leadership as the key to promoting high-quality clinical care and transforming services to achieve greater levels of excellence ${ }^{[18]}$. Contributions to understanding the concept of clinical leadership and characteristics of clinical leaders have been offered by a number of authors and a great deal has been added to an understanding of this topic as a result ${ }^{[1,19-25]}$. As such, a summary of clinical leadership attributes are identified as: motivating and inspiring, approachable, clinically knowledgeable and clinically competent. They are effective communicators, empowered, visible in practice and base their actions on their values and beliefs $^{[1,8-10]}$.

Jonas, McCay and Keogh go on to describe clinical leaders as "clinical healthcare staff undertaking the roles of leadership: setting, inspiring and promoting values and vision and using their clinical experience and skills to ensure the needs of the patient are the central focus in the organization's aims and delivery” ${ }^{[18]}$. They also emphasize the important and indeed 
vital link clinical leaders have to the implementation and development of evidence-based practice and support for contemporary health policy.

To generate innovation and implement change (particularly change that is based on clear clinical evidence) clinical leaders need to apply processes, tools, models and structures supported by clear policies. Otherwise sustainable change and genuine innovation is difficult to achieve ${ }^{[1,18]}$.

Table 1. Clinical Leadership Characteristics Summary

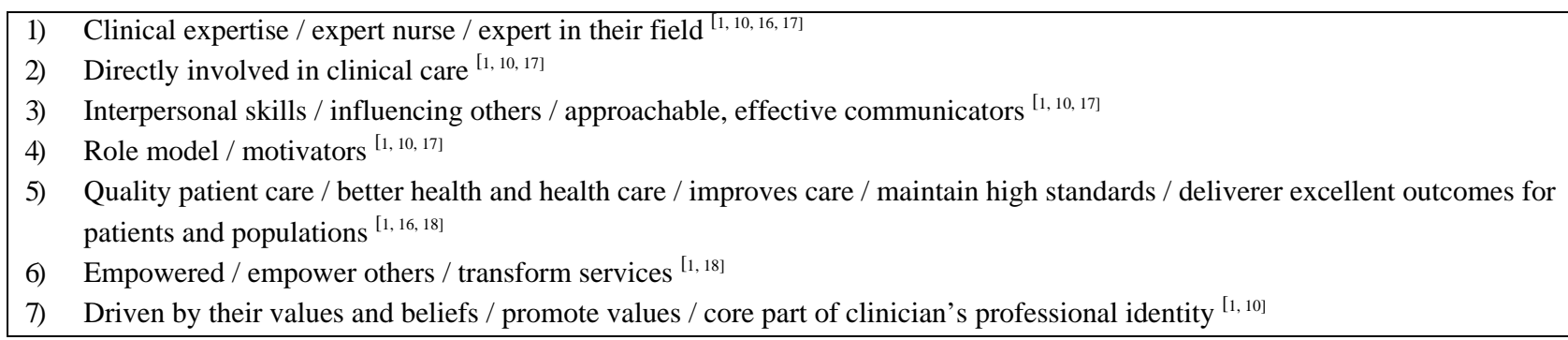

A summary of the literature identified above suggests that clinical leaders are seen as clinical experts who are directly involved in providing clinical care. They are approachable motivators and effective communicators who can influence others and act as role models ${ }^{[1,18]}$. They are involved in quality patient care, making health and health care better and improving care by maintaining high standards so that they deliverer excellent outcomes for patients and populations. They are empowered, or empower others to transform services because they act on their values and beliefs or promote the values they hold to be true and because they are a core part of the clinician's professional identity (see Table 1).

\section{Who are the clinical leaders}

To effectively influence or support innovation in practice there is a need to recognize who the clinical leaders are - they are found at all clinical levels in an organization ${ }^{[18]}$ and are likely not to be managers or administrators or have titled or senior non-clinical positions ${ }^{[1,10,26]}$. In two research studies ${ }^{[1,8-10]}$ by Stanley exploring the attributes and issues of clinical leadership the characteristic least associated with clinical leadership was "controlling" (78\% in the first and $84 \%$ in the second study). Therefore, clinical staff (with any sort of managerial role) that were seen to be in positions of "controlling" others were less likely to be seen as clinical leaders. Clinical leaders were more likely to be found at the bed side ${ }^{[17]}$, on night shift or indeed any shift, holding the hand of an elderly person as they explain their client's treatment options, or working in a minor injury clinic or A\&E department, or in a medical ward, or person's home or any clinical environment. Clinical leaders are in every clinical environment and they can be at any level where clinical staff operate, recognized for displaying the characteristics above (see Table 1).

Mangers and senior non-clinical health care staff often have a significant influence on clinical services and on the quality, care, service and professional agenda, but they are seldom seen by clinical staff as clinical leaders ${ }^{[1]}$.They may still be leaders, in the management, political or educational domains. They may be visionary, creative, people who are care and service focused. However, they are seldom seen as clinical leaders because they seldom capture in their managerial role all of the attributes suggested in Table $1^{[1,26]}$.

There are a raft of other factors that impact on the capacity of individual health service staff to fulfill a leadership role such as the organizational culture, team working skills, resources available, managerial structures and conflict management skills. However, following considerable research over the past decade, it is clear that clinical leaders from any professional group are more likely to be the most senior clinically based staff ${ }^{[1]}$. Although, it is acknowledged that clinical leaders are found at any level ${ }^{[17]}$ as long as they embody the attributes and characteristics outlined in Table 1 . However, the key to 
their identification is seen as being a match between their actions and their values and beliefs. In this regard, clinical leaders were seen to be displaying a congruent leadership approach ${ }^{[1,8-10]}$.

\section{Innovation}

Innovation is to do with bringing about a better future and is the result of change that is designed or planned, or it can be the result of acting in ways that are consistent with or congruent with our values and beliefs. Innovation can also mean bringing into existence something new that can be sustained and which has some value or utility. In effect, innovation results in a breakthrough of some sort ${ }^{[27]}$.

Clinical leaders relate to innovation and change by considering creative solutions, by putting their vision or values into action and by being the force for change or acting out (role modeling) their values and by having it be part of who they are. As such clinical leaders who display Congruent Leadership ${ }^{[1,8-10]}$ are placed at the heart of supporting clinical innovations and change. Therefore, innovation rests in the hands of clinical leaders in the same way that the day to day application of care or quality rests in their hands. It is with clinical leaders that organizations should be placing their future investment. Because once identified and supported clinical leaders will be in a position to identify were innovations can be made and where change in practice can best be directed.

Selman is of the view that our attitude to innovation rests on our perspective of change ${ }^{[27]}$. Selman identified six different ways we can relate to change, with our dominant perspective opening or closing our attitude to possibilities or opportunities for innovation. Thus our dominant perspective to change will reflect our inclination to be innovative (or not) and our response to innovation ${ }^{[27]}$ (see Table 2).

\section{Case Study 2:}

Jack was a triage nurse. He noticed that patients with minor complaints crowded the A\&E department waiting to be seen by a doctor. The list of patients grew as doctors were often in short supply or busy with more acute patients. Jack had read about the effectiveness of Nurse Practitioners in dealing with minor injury patients in A\&E and drafted a proposal to recruit and use Nurse Practitioners in their A\&E department.

Management was reluctant due to a perceived cost blowout and the doctors felt threatened. But he persisted (in spite of considerable opposition) and gathered respectable research publications that demonstrated the positive impact of Nurse Practitioners in A\&E. He also accessed audit and attendance data from his own department that supported his observations about long waiting times for minor injury patients. Jack even made himself available for study so that if the department changed its view, he could become a Nurse Practitioner. Years passed, with patient's waiting while they and the A\&E staff (doctors and nurses) became increasingly frustrated and angry. Jack finished his studies and re-initiated his proposal offering himself as a Nurse Practitioner to trial a new "fast track" system for him to see patients that presented with low priority "minor injury” conditions.

A year later Jack was now one of 5 Nurse Practitioners (with other nurses enrolled for further study). The Nurse Practitioners now saw up to $40 \%$ of the patients that presented at A\&E, many with serious medical conditions and the waiting times and frustrations in the A\&E were significantly reduced. Jack’s proposal was not new, but his persistence and belief that it could make a significant difference to the situation for patients in the A\&E showed that he was being the force for change, acting it out in his daily life and creating a solution by putting his values and vision into action.

If innovation results from a planned for or deliberate act, or if it can be the result of acting in ways that are consistent with (or congruent) with our values and beliefs, then it may be that the real agents of change and innovation in the health service are clinical leaders. It was identified that clinical leaders are more likely to demonstrate Congruent leadership ${ }^{[1,8-10]}$, rather 
than other types of leadership approaches, therefore they can be seen to be acting to "Bring Forth", or show "Mastery" when faced with or initiating change. In the example case study 2 offered above, it could only have been a clinical leader, visible in practice that initiated the proposal to change the bars in the toilet. The unit manager or hospital administration would most likely never have been in a position to recognize the need for proposing the change given the diminished likelihood of their having to respond to the bell or enter the toilet.

Table 2. The Six Attitudes for relating to change ${ }^{[27]}$

1) Resistance... “counter innovation”: Seen as the most common way to relate to change. Involves disagreement, covert resistance, non-cooperation, procrastination, arguing, rationalizing, sabotage....all to counter innovation. Resistance will either lead to finding ways to cope or chronic suffering and resignation. Resistance often places us in positions of being either victims, spectators of circumstances or non-participators in creating our future. Destroying our possibilities and power.

2) Coping: About problem solving and overcoming barriers to change. Still counter innovative as change is only approached as a re-action to circumstances. Here people employ “work around” or "in spite of” strategies,

3) Responding: The choice is made to act, about being responsible.

4) Choosing: Embracing the change, a commitment to larger possibilities.

5) Bringing Forth: Outside the box thinking. Creating a solution, putting your vision or values into action, leading on an issue. Taking a stand.

6) Mastery: Being the force for change acting it out in your daily life. Having it be part of who you are.

\section{I nnovation hinderers and helps}

Even the most effective clinical leaders recognize that barriers and obstacles hinder the advancement of innovation and change. Table 3 and 4 offer some insights into what might hinder or help innovation in healthcare practice.

Table 3. What might hinder innovation in the healthcare?

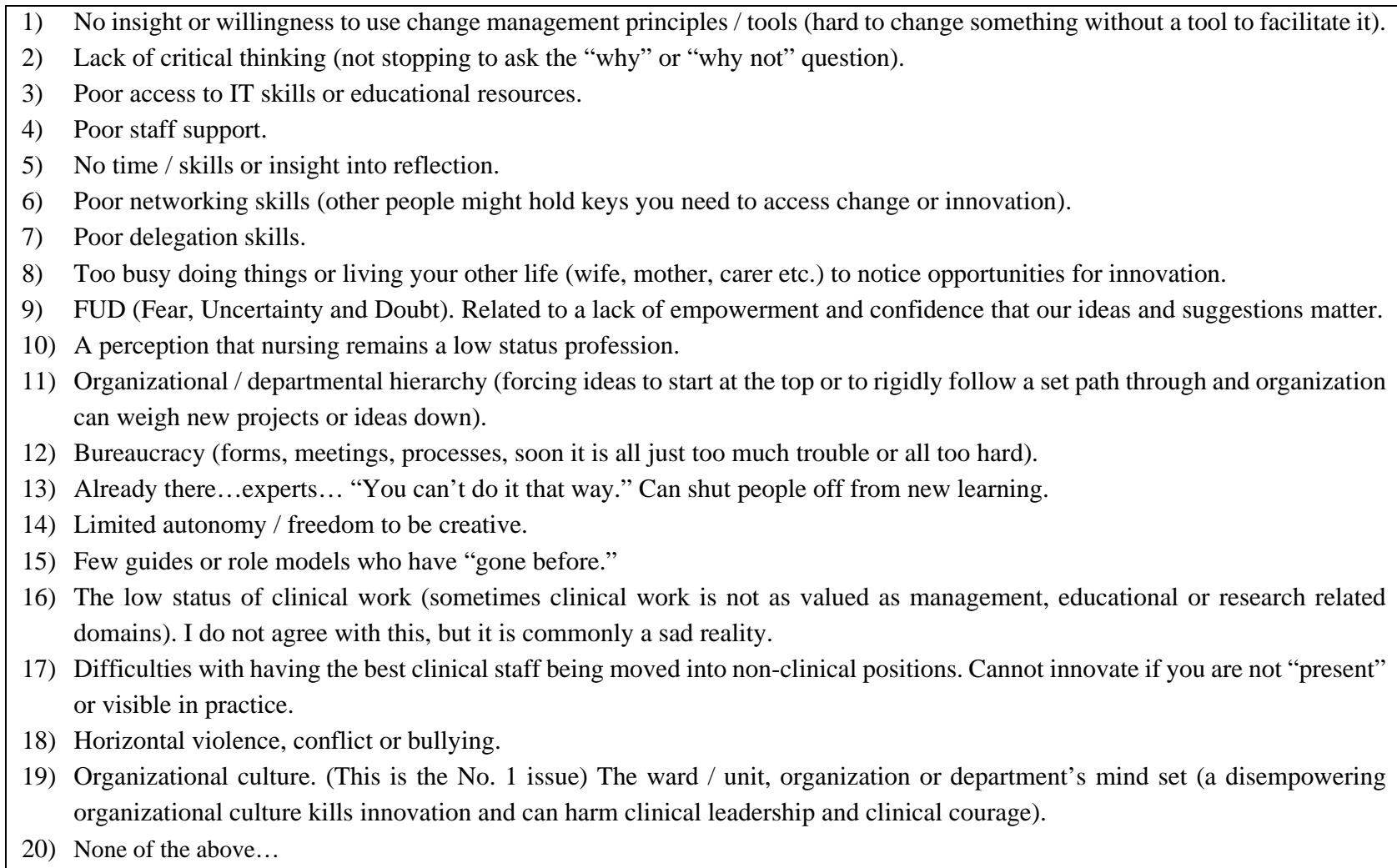


These suggestions are not a definitive list and many others could be proposed. As well it is proposed that it may be that "None of the above" will hinder change or innovation, implying that none of these barriers to innovation may be the real reason change and innovation are stifled. Indeed, this final point implies that empowered clinical leaders may not regard barriers as insurmountable obstacles. Indeed, if an obstacle free road were the only path to achieving things, would anything ever get done, developed, created, invented, and changed? It could be argued that obstacles bind a team and create challenges that motivate and prompt leaders ${ }^{[28]}$. Effective clinical leaders may demonstrate Rogers perspective on empowerment, where it is proposed that empowerment comes from within ${ }^{[29]}$ and isn't the path, but the walk and the choice about which path to take.

Clinical leaders were identified as being empowered, visible role models ${ }^{[17]}$ for their values and beliefs ${ }^{[1]}$ and perhaps it is (in part) these qualities that have allowed clinical leaders to initiate innovation and support change. There are many other factors that might foster or help the development of innovation and a number are suggested in Table 4 .

Table 4. What might help innovation in the Health Service

1) Understanding change management principles and tools.

2) An organizational culture that is open and supportive.

3) A capacity to take risks.

4) Being there: inspiration often comes from being close to the action = visibility.

5) Going to the source: Having insight into or the direct involvement of patients or service users (not about health service experts...) it is about gaining insight from the actual users of the service.

6) Having clinical support / mentorship / guides / role models.

7) Access to IT skills and educational resources.

8) A willingness to follow and develop your passion (nurture your values and beliefs)...courage...and strength to challenge or change the rules.

9) Reflection: knowing where you are and where you want to go and what your values and beliefs are. Insight into yourself.

10) Create a bug list ${ }^{[30]}$. A list of things that "bug” you and ask yourself the "why" and "why not" questions?

11) Observe...step back and use your child's eye ${ }^{[30]}$.

12) Observe the right people. These may be clinical leaders. People who follow direction perfectly and can’t imagine a different course of action are not much help for innovation. You learn from people who push the boundaries. Would we have Nurse Practitioners now if someone didn't push for an alternate way?

13) Little innovations matter doesn't have to be the big idea.

14) Recognize and acknowledge clinical heroes.

15) The best way to have a good idea is to have lots of ideas ${ }^{[30]}$.

16) Brainstorm / mind map / reflect / team meetings, whatever it takes. But give yourself or your team permission and time to do this.

17) Try things out (dreaming will not work) need to build prototypes / samples / trials (don’t know if you don't try).

18) Allow change to have an opportunity to impact on your ideas.

19) Use show and tell time (in handover or at ward meetings) and give people a fair hearing.

20) Share or tell the stories of your innovative ideas (at meetings and conferences).

21) May be lots of others...

\section{Conclusion}

The first objective of a health care organization should be to identify their clinical leaders. The second should be to facilitate these people to see their own leadership potential, because the most limiting factor for the development of clinical leaders is that even if an organization can see their clinical leaders’ potential and are prepared to support and nurture them, the clinical leaders (having been indoctrinated to see only leaders with titled positions, visionary attributes or authority) seldom see their own leadership potential ${ }^{[1]}$. In Stanley's 2006 study only half the clinical leaders nominated as such recognized themselves as clinical leaders ${ }^{[8,9]}$. 
Innovation and change is not about processes or structure, although these are needed in complex, chaotic organizations. They are about courageous people (clinical leaders) who are prepared to act and positively impact on quality patient care and advance health care services and care standards. It is proposed that effective clinical leadership leads to innovation. Innovation leads to change and that change leads to improvements in care, service, quality and professionalism. It is clear that there has been a massive investment in leadership development across the globe over the past decade ${ }^{[31]}$. This is commendable and the intent has been sound, although a lack of understanding about what clinical leadership means and who the clinical leaders are will jeopardize the potential for innovation that sits within each hospital ward and clinic. Therefore, it is proposed that clinical leaders need to be recognized, by their organizations and by themselves, for genuine clinical innovation and change to be forthcoming.

\section{References}

[1] Stanley D. Clinical Leadership: Innovation into action. Palgrave Macmillan, Melbourne. 2011.

[2] Baker GR, Norton PG, Flintoff V. The Canadian adverse events study: The incidence of adverse events among hospital patients in Canada. Canadian Medical Association. 2004; 17(10): 1678-1686. PMid:15159366 http://dx.doi.org/10.1503/cmaj.1040498

[3] Cook MJ. The renaissance of clinical leadership. International Nursing Review. 2004; 48(1): 38-46. PMid:11316275 http://dx.doi.org/10.1046/j.1466-7657.2001.00040.x

[4] Alleyne J, Jumaa MO. Building the capacity for evidence based Clinica nursing leadership: the role of executive co-coaching and group clinical supervision for quality patient services. Journal of Nursing Management. 2007; 15(2): 230-243. PMid:17352707 http://dx.doi.org/10.1111/j.1365-2834.2007.00750.x

[5] Wong C, Cummings G. The relationship between nursing leadership and patient outcomes: a systematic review. Journal of Nursing Management. 2007; 15(5): 508-521. PMid:17576249 http://dx.doi.org/10.1111/j.1365-2834.2007.00723.x

[6] Sirola-Karvinen P, Hyrkas K. Clinical supervision for nurses in administrative and leadership positions: a systematic literature review of the studies focusing on administrative clinical supervision. Journal of Nursing Management. 2006; 14(8): 601-609. PMid: 17054733 http://dx.doi.org/10.1111/j.1365-2934.2006.00719.x

[7] Murphy J, Quillinan B, Carolan M. Role of clinical leadership in improving patient care. Nursing Management. 2009; 16(8): 26 $-29$.

[8] Stanley D. In command of care: Clinical nurse leadership explored. Journal of Research in Nursing. 2006(a); 2(1): $20-39$.

[9] Stanley D. In Command of Care: towards the theory of congruent leadership. Journal of Research in Nursing. 2006(b); 11(2): 134 $-144$.

[10] Stanley D. Congruent leadership: Values in action. Journal of Nursing Management. 2008; 16: 519-524. PMid:18558922 http://dx.doi.org/10.1111/j.1365-2834.2008.00895.x

[11] Hall ML. Shaping organizational culture: A practitioner’s perspective. Peak Development Consulting. 2005; 11(1): 1-16.

[12] Handy C. Understanding Organizations. (4th Ed.) London: Penguin Books. 1999.

[13] Department of Health (Australia) [Internet]. 2011. Available from: http://www.yourhealth.gove/internet/yourhealth/publishing.nsf/Content/natleadclinicgroup

[14] Harper J. Clinical leadership - Bridging theory and practice. Nurse Educator. 1995; 20(3): 11-12. http://dx.doi.org/10.1097/00006223-199505000-00011

[15] McKinsey Quarterly. 2007(Cited in: Stanton E Lemer C, Mountford J. 2010. Clinical leadership: Bridging the divide. Quay Books, London).

[16] Lett M. The concept of clinical leadership. Contemporary Nurse. 2002; 12(1): 16 -20. PMid:12013513 http://dx.doi.org/10.5172/conu.12.1.16

[17] Cook M. The attributes of effective clinical nurse leaders. Nursing Standard. 2001; 15(35): 33-36.

[18] Jonas, McCay and Keogh. (chapter 1, sited in ABC of Clinical Leadership, edited by T. Swanwick and J. McKimm (Wiley-Balckwell, West Sussex). 2011.

[19] Cosens M, Ibbotson T, Grimshaw J. Identifying opinion leaders in ward nurses: A pilot study. NT Research. 2000; 5(2): 148-155. http://dx.doi.org/10.1177/136140960000500214

[20] Firth K. Ward leadership: Balancing the clinical and managerial roles. Professional Nurse. 2002 April; 17(8): 486-489. PMid:11997964

[21] McCormack B, Hopkins E. The development of clinical leadership through supported reflective practice. Journal of Clinical Nursing. 1995; 4(3): 161-168. http://dx.doi.org/10.1111/j.1365-2702.1995.tb00201.x 
[22] McCormack B, Garbett R. The characteristics and skills of practice developers. Journal of Clinical Nursing. 2003; 12 (3): 317-325. PMid:12709105 http://dx.doi.org/10.1046/j.1365-2702.2003.00726.x

[23] Frankel A. What leadership styles should senior nurses develop? Nursing Times. 2008; 104(35): 23-24.

[24] Stanton E, Lemer C, Mountford J. Clinical leadership: Bridging the divide. London: Quay Books. 2010.

[25] Swanwick T, McKimm J. ABC of Clinical Leadership. Wiley Blackwell. BMJ Books, Oxford. 2011.

[26] Stanley D. Role conflict: leaders and managers. Nursing Management. 2006c; 13(5): 31-37.

[27] Selman J. Leadership and Innovation: Related circumstances and change. Paracomm Partners International [Internet]. 2004. Available from: http://www.PARACOMM.com

[28] Kouzes JM, Posner BZ. The truth about leadership: The no-fads, heart of the matter facts you need to know. San Francisco: Jossey-Bass. 2010.

[29] Rogers C. Carl Rogers on Personal Power. New York: Delacorte. 1979.

[30] Kelly T. The Art of Innovation. New York, Doubleday Books. 2001.

[31] National Health Service Leadership Centre. NHS Leadership Qualities Framework. London: NHS Leadership Centre. 2002. 